\title{
openheart Rapid early rise in heart rate on treadmill exercise in patients with asymptomatic moderate or severe aortic stenosis: a new prognostic marker?
}

\author{
John B Chambers, ${ }^{1}$ Ronak Rajani, ${ }^{1}$ Denise Parkin, ${ }^{1}$ Sahrai Saeed ${ }^{1,2}$
}

To cite: Chambers JB, Rajani R, Parkin $\mathrm{D}$, et al. Rapid early rise in heart rate on treadmill exercise in patients with asymptomatic moderate or severe aortic stenosis: a new prognostic marker?. Open Heart 2019;6:e000950. doi:10.1136/ openhrt-2018-000950

Received 10 0ctober 2018 Accepted 15 November 2018

Check for updates

\section{(c) Author(s) (or their} employer(s)) 2019. Re-use permitted under CC BY-NC. No commercial re-use. See rights and permissions. Published by BMJ.

${ }^{1}$ Cardiothoracic Centre, Guy's and St Thomas' Hospital,

London, UK

${ }^{2}$ Department of Heart Disease, Haukeland University Hospital, Bergen, Norway

Correspondence to Dr John B Chambers; jboydchambers@aol.com

\section{ABSTRACT}

Objective To examine the clinical significance and prognostic value of an early rapid rise in heart rate (RR$\mathrm{HR}$ ) in asymptomatic patients with moderate or severe aortic stenosis (AS).

Methods We retrospectively assessed the prospectively collected data from 306 patients (age $65 \pm 12$ years, 33\% women) with moderate $(n=204)$ or severe AS $(n=102)$ with a median follow-up of 25 months (mean $34.9 \pm 34.6$ months). All had echocardiography and modified Bruce exercise treadmill tests (ETT). RR-HR was defined as achieving $85 \%$ target HR or $\geq 50 \%$ increase from baseline in the first $6 \mathrm{~min}$. The outcome measures were revealed symptoms during ETT, aortic valve replacement (AVR) and all-cause mortality.

Results RR-HR occurred in 77 (25\%) and 64\% developed revealed symptoms (postive predictive value $64 \%$ and negative predictive value $84 \%$ ). On univariate Cox regression analyses in patients with severe AS, RR-HR was associated with AVR (HR 3.32, 95\% Cl 2.03 to 5.45 , $\mathrm{p}<0.001)$ but not with all-cause mortality (HR $0.04,95 \% \mathrm{Cl}$ 0.13 to $9.21, p=0.798$ ). In patients with moderate AS, RR-HR was associated with all-cause mortality (HR 2.67, $95 \% \mathrm{Cl} 1.09$ to $6.56, \mathrm{p}=0.032$ ), but not with AVR (HR $1.35,95 \% \mathrm{Cl} 0.92$ to $1.98, \mathrm{p}=0.127)$. These associations remained significant in multivariate Cox regression analyses after adjustment for age, sex, hypertension, coronary artery disease, abnormal blood pressure response, Doppler stroke volume and mean pressure gradient (both $p<0.001$ ).

Conclusions RR-HR was associated with the development of revealed symptoms. It predicted revealed symptoms on serial ETT, AVR in severe AS and all-cause mortality in moderate AS. RR-HR may be a useful new measure to define risk in AS.

\section{INTRODUCTION}

International guidelines recommend formal exercise testing for patients with apparently asymptomatic severe aortic stenosis (AS) because revealed symptoms are a class I indication for aortic valve replacement (AVR) and an abnormal blood pressure (BP) response a class IIa indication. ${ }^{1}$ Despite this exercise testing is underutilised, ${ }^{2}$ partly for logistic reasons and partly from concern over safety although we recently showed that the risk of adverse events is close to zero. ${ }^{3}$ There is also lingering concern that revealed symptoms are subjective and less valid than spontaneous symptoms taken from the history. ${ }^{4}$ However, we showed that the stroke volume fell during early exercise in those developing symptoms but rose in those remaining symptom free. ${ }^{5}$ The cardiac index was similar in the two groups suggesting that an augmented rise in heart rate (HR) in those deveanloping symptoms occurred as an adaptive response to maintain cardiac output. ${ }^{5}$ It is therefore possible thatan early rapid rise in HR (RR-HR) may identify patients who develop symptoms later in exercise. It is our practice to exercise patients with moderate AS since their prognosis may not be benign. ${ }^{6-8} \mathrm{We}$ recently showed that symptoms were revealed in nearly $20 \%$ with moderate AS and $40 \%$ with severe AS. ${ }^{3}$ The aim of the present study was therefore to determine in patients with moderate or severe AS whether: (1) an early RR-HR during an exercise treadmill test (ETT) preceded the development of revealed symptoms later in the test and (2) whether it predicted events during follow-up.

\section{METHODS \\ Patient population}

The Exercise Testing in Aortic Stenosis (EXTAS) study is a retrospective cohort study of data collected prospectively between January 2000 and May 2017. ${ }^{3}$ A total of 651 patients aged $>18$ years with moderate (effective orifice area $1.0-1.5 \mathrm{~cm}^{2}$ ) or severe (effective orifice area $\left.<1.0 \mathrm{~cm}^{2}\right) \mathrm{AS}^{910}$ were assessed in a specialist heart valve clinic at Guy's and St Thomas' Hospital. All patients underwent an ETT at presentation and most were 
Between January 2000 and May 2017651 patients $>18$ years

with moderate or severe AS were assessed at heart valve clinic

Excluded

Spontaneous symptoms $(\mathrm{n}=283)$

Chronic obstructive pulmonary disease $(\mathrm{n}=24)$

Severe mitral regurgitation $(\mathrm{n}=12)$

Severe mitral stenosis $(\mathrm{n}=4)$

Severe aortic regurgitation $(\mathrm{n}=5)$

Peripheral vascular disease $(\mathrm{n}=2)$

Skeletal disorders $(\mathrm{n}=3)$

Anemia $(\mathrm{n}=2)$

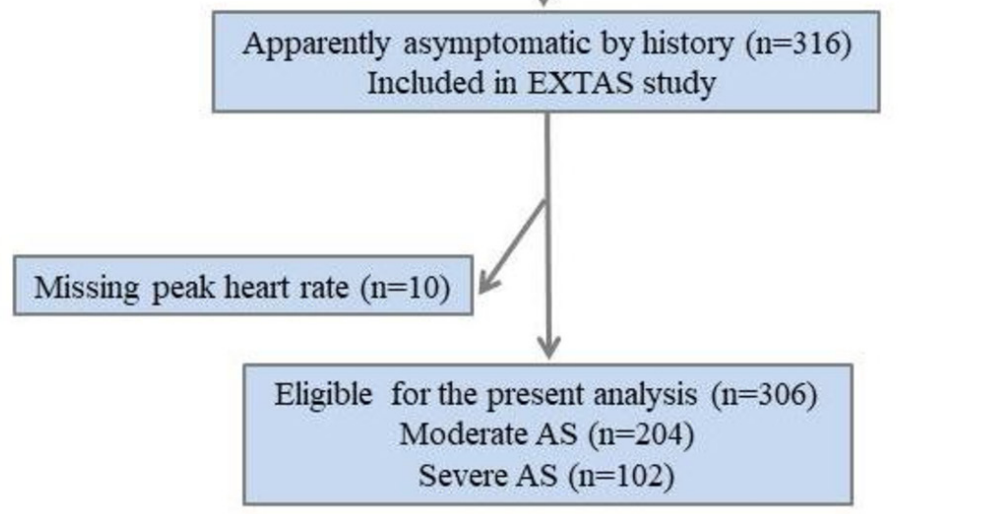

Figure 1 Flow chart of the study population. AS, aortic stenosis; EXTAS, Exercise Testing in Aortic Stenosis.

restudied when their AS crossed the threshold between moderate and severe, and thereafter annually. Baseline data including clinical characteristics, ETT and echocardiography was used in the present analysis. A total of 283 patients were excluded from the study because of the presence of spontaneous symptoms justifying surgery, 21 patients due to more than moderate disease of other valves (12 patients with severe mitral regurgitation, four with severe mitral stenosis and five with severe aortic regurgitation), 24 owing to chronic obstructive pulmonary disease, two to peripheral vascular disease, three to skeletal disorders and two to anaemia. The remaining 316 patients $(49 \%)$ were apparently asymptomatic on the history and eligible for ETT. Of these, 10 patients were excluded due to an unrecorded peak HR, leaving 306 available for the present analysis (figure 1). Hypercholesterolaemia was defined as treatment with lipid-lowering drugs. Obesity was defined as body mass index $\geq 30 \mathrm{~kg}$ / $\mathrm{m}^{2}$. Resting clinic BP prior to ETT was measured with a semiautomatic device with the patient resting for 5-10 min in the sitting position. Hypertension was defined from a history of elevated $\mathrm{BP}$ values, past or current treatment with antihypertensive agents or a BP at the baseline clinic visit $>140 / 90 \mathrm{~mm} \mathrm{Hg}{ }^{3}$ The double product (rate pressure product), a prognostically validated index of myocardial oxygen consumption, was defined as systolic
BP multiplied by the peak HR. ${ }^{11}$ Prior to surgical or transcutaneous AVR, all patients underwent conventional coronary angiography. Coronary artery disease was defined as previous myocardial infarction, coronary artery bypass grafting or percutaneous coronary intervention, or angiographic evidence of coronary artery disease ( $>70 \%$ stenosis of one or more main epicardial artery). The study was managed and conducted in accordance with the Declaration of Helsinki and latest Good Clinical Practice guidelines.

\section{ETT protocol}

ETTs were performed according to American College of Cardiology/American Heart Association practice guidelines using a Bruce protocol modified by two warm-up stages so most patients at any age can exercise for 9 min which is equivalent to $3 \mathrm{~min}$ of a standard Bruce protocol. ${ }^{1213}$ The test was stopped prematurely for symptoms (significant breathlessness or any chest constriction or dizziness), progressive ventricular ectopy $>3$ beats, new atrial fibrillation, a sustained fall in systolic BP $>20 \mathrm{~mm} \mathrm{Hg}$ from the previous stage or more than $5 \mathrm{~mm}$ ST segment depression. ${ }^{3}$ Significant symptoms (breathlessness, chest tightness, dizziness, the presence of distress, inability to speak and facial pallor) were differentiated clinically from physiological breathlessness at high workload. ${ }^{3}$ An 
abnormal BP response was defined as a sustained fall in systolic $\mathrm{BP} \geq 20 \mathrm{~mm} \mathrm{Hg}$ below the previous stage or baseline level. ${ }^{14}$ The following measures were recorded: exercise time, exercise capacity in metabolic equivalents (METs), maximum systolic and diastolic BP, ST segment depression in mm. One MET is defined as the energy expended at rest which is equal to a body oxygen consumption of nearly $3.5 \mathrm{~mL} / \mathrm{kg}$ of body weight for an average adult. ${ }^{15}$ METs were calculated from the speed and gradient of the treadmill by the machine's software using the formula $($ METS $=(($ speed $\times 0.1)+($ gradient $/ 100 \times 1.8 \times-$ speed)+3.5)/3.5), where speed is measured in $\mathrm{m} / \mathrm{s}$ and gradient as a percentage. Predicted peak HR was calculated according to the Astrand formula (220-age). ${ }^{16}$ An early RR-HR during ETT was defined as achieving at least $85 \%$ of target HR or $\geq 50 \%$ increase from baseline within the first 6 min. Six minutes was chosen because it represents the end of the warm-up phase. However, there is little in the literature to guide this definition.

\section{Transthoracic echocardiography}

Echocardiographic data were obtained using commercially available ultrasound systems (Vingmed system 5, 7, 9 GE Medical, Milwaukee, Wisconsin, USA, or a Philips 'Epiq 7' cardiac ultrasound machine). The recommended methodology for the assessment of severity of AS, left ventricular (LV) wall thicknesses, chamber dimensions, stroke volume and ejection fraction was standardised as part of our retrospective analysis and measured according to prevailing joint European and US guidance. ${ }^{9}{ }^{1017} \mathrm{LV}$ hypertrophy was diagnosed as LV mass $>46.7 \mathrm{~g} / \mathrm{m}^{2.7}$ in women and $49.2 \mathrm{~g} / \mathrm{m}^{2.7}$ in men, respectively, and relative wall thickness as $2 \times \mathrm{LV}$ posterior wall thickness/LV internal radius at end-diastole, and considered increased if $\geq 0.430 .{ }^{17}$ The ratio of PP to $\mathrm{SVi}$ ( $\mathrm{PP} / \mathrm{SVi}$ ) was used as an indirect measure of systemic arterial stiffness. ${ }^{18} \mathrm{LV}$ stroke work was defined as: systolic BP.SV converted to gram-metres by multiplying by 0.0144$).{ }^{19}$ Valvuloarterial impedance $\left(\mathrm{Z}_{\mathrm{va}}\right)$, a measure of resting global LV afterload was calculated as: (systolic $\mathrm{BP}+$ mean aortic pressure gradient)/stroke volume index. ${ }^{20}$

\section{Study end points}

Outcomes were revealed symptoms on ETT, AVR (either surgical or via a transcatheter approach) and all-cause mortality. Indications for AVR on patients asymptomatic on the history were revealed symptoms on ETT or spontaneous symptoms developing during follow-up. Follow-up time was calculated from the baseline ETT until AVR, death or censoring on 19 September 2017.

\section{Statistical analyses}

SPSS V.24.0 was used for data management and statistical analyses. Continuous variables were presented as mean $\pm \mathrm{SD}$ and categorical variables as percentages. Comparison between groups was by a Student's t-test or $\chi^{2}$ test for parametric and non-parametric data as appropriate. Correlates of RR-HR during ETT were tested in univariate and multivariate logistic regression analyses. Bivariate associations between continuous variables were performed with Pearson's correlation coefficients. Kaplan-Meier curves were used to examine cumulative event rates and the difference between groups was tested using a log-rank test. Cox proportional hazard models were used to assess the association between RR-HR and outcomes. A $p$ value of $<0.05$ was considered to be statistically significant.

\section{RESULTS}

\section{Baseline characteristics}

The mean age of the study population was $65 \pm 12$ years and $67 \%$ were men and $33 \%$ women. At baseline, 204 (66.7\%) had moderate AS and $102(33.3 \%)$ had severe AS. Patients with severe AS were older, but did not differ in body surface area, smoking status and clinic BP compared with patients with moderate AS (table 1). Patients with moderate AS were more likely to have coronary artery disease and hypercholesterolaemia, while there was no difference in the proportion of other comorbidities. ACE inhibitors were more frequently used by patients with severe AS (table 1). LV ejection fraction, systemic arterial stiffness (pulse pressure/stroke volume index), stroke work and the prevalence of LV hypertrophy were comparable in both groups, while valvuloarterial impedance was significantly higher in patients with severe AS (table 1).

\section{Exercise treadmill parameters}

There were no significant differences in exercise measurements between patients with moderate and severe AS (table 2).

Symptoms were revealed in $87(28.4 \%)$ patients more frequently with severe than moderate AS (36.3 vs $24.5 \%$; $\mathrm{p}=0.032)$. Women had shorter exercise duration than men $(8.2 \pm 4.2$ vs $10.4 \pm 4.3 \mathrm{~min}, \mathrm{p}<0.001)$ and lower METs (7.6 \pm 4.3 vs $9.2 \pm 4.5 ; \mathrm{p}=0.003$ ), but achieved similar peak HR $(134 \pm 27$ vs $134 \pm 24 \mathrm{bpm}$; $\mathrm{p}=0.986)$.

\section{Early RR-HR}

An early RR-HR occurred in 77 (25\%) patients. These were older and had a higher proportion of females, obesity and hypertension than those with a normal HR response (table 3 ).

$\mathrm{Z}_{\mathrm{va}}$ was significantly higher, left atrium was larger and aortic root was smaller in the RR-HR group, but there were no differences in the severity of AS, stroke volume index, resting HR or LV mass between the groups. Patients with RR-HR had shorter exercise times than those with a normal HR response $(5.3 \pm 2.3$ min vs $11.2 \pm 3.9 \mathrm{~min} ; \mathrm{p}<0.001)$ and $49(64 \%)$ developed limiting symptoms later in the same exercise test. In a univariate logistic regression analysis, beta blocker treatment was not associated with RR-HR (OR $0.67,95 \%$ CI 0.30 to 1.45 , $\mathrm{p}=0.298$ ). The positive predictive value (PPV) of RR-HR for revealed symptoms was $64 \%$ and negative predictive value (NPV) $84 \%$. Of those with revealed symptoms, $56 \%$ had RR-HR (PPV 56\% and NPV 87\%). 
Table 1 Baseline clinical and echocardiographic characteristics of the study population according to the severity of AS

\begin{tabular}{|c|c|c|c|c|}
\hline & Total $(n=306)$ & Moderate AS $(n=204)$ & Severe AS $(n=102)$ & $P$ value \\
\hline \multicolumn{5}{|l|}{ Demographic and clinical data } \\
\hline Age, years & $65 \pm 12$ & $64 \pm 12$ & $69 \pm 11$ & $<0.01$ \\
\hline Male, female $\%$ & 67,33 & 70,30 & 61,39 & 0.134 \\
\hline Obesity & $80(26 \%)$ & $55(27 \%)$ & $25(25 \%)$ & 0.944 \\
\hline Smokers & $147(48 \%)$ & $96(47 \%)$ & $51(50 \%)$ & 0.586 \\
\hline Coronary artery disease & $152(50 \%)$ & $118(58 \%)$ & $36(35 \%)$ & 0.001 \\
\hline Diabetes mellitus & $43(14 \%)$ & $31(15 \%)$ & $12(12 \%)$ & 0.409 \\
\hline Previous stroke or transient ischaemic attack & $37(12 \%)$ & $28(14 \%)$ & $9(9 \%)$ & 0.233 \\
\hline Atrial fibrillation & $43(14 \%)$ & $21(10 \%)$ & $22(21 \%)$ & 0.056 \\
\hline Hypercholesterolaemia & $202(66 \%)$ & $144(71 \%)$ & $58(57 \%)$ & 0.029 \\
\hline Clinic systolic BP, mm Hg & $142 \pm 19$ & $140 \pm 18$ & $145 \pm 21$ & 0.052 \\
\hline Clinic diastolic BP, mm Hg & $82 \pm 13$ & $81 \pm 12$ & $86 \pm 11$ & 0.001 \\
\hline Hypertension & $223(73 \%)$ & $146(72 \%)$ & $77(75 \%)$ & 0.565 \\
\hline Antihypertensive treatment & $199(65 \%)$ & $133(65 \%)$ & $66(65 \%)$ & 0.992 \\
\hline Beta blockers & $101(33 \%)$ & $65(32 \%)$ & $36(35 \%)$ & 0.805 \\
\hline Diuretics & $92(30 \%)$ & $63(31 \%)$ & $29(28 \%)$ & 0.581 \\
\hline Calcium blockers & $80(26 \%)$ & $49(24 \%)$ & $31(29 \%)$ & 0.618 \\
\hline ACE inhibitors & $60(20 \%)$ & $49(24 \%)$ & $11(11 \%)$ & 0.036 \\
\hline ARB inhibitors & $37(12 \%)$ & $27(13 \%)$ & $10(10 \%)$ & 0.447 \\
\hline Alpha blockers & $25(8 \%)$ & $19(9 \%)$ & $6(6 \%)$ & 0.368 \\
\hline \multicolumn{5}{|l|}{ Echocardiographic data } \\
\hline LV end-diastolic diameter, $\mathrm{cm}$ & $4.6 \pm 0.7$ & $4.6 \pm 0.6$ & $4.5 \pm 0.7$ & 0.301 \\
\hline Interventricular septal thickness, $\mathrm{cm}$ & $1.29 \pm 0.26$ & $1.27 \pm 0.25$ & $1.35 \pm 0.28$ & $<0.018$ \\
\hline Posterior wall thickness, $\mathrm{cm}$ & $1.12 \pm 0.22$ & $1.10 \pm 0.20$ & $1.15 \pm 0.26$ & $<0.036$ \\
\hline LV mass index, $\mathrm{g} / \mathrm{m}^{2.7}$ & $52 \pm 17$ & $50 \pm 16$ & $55 \pm 20$ & 0.098 \\
\hline LV hypertrophy & $165(54 \%)$ & $106(52 \%)$ & $60(59 \%)$ & 0.357 \\
\hline LV ejection fraction \% & $60 \pm 7$ & $60 \pm 7$ & $60 \pm 6$ & 0.821 \\
\hline Peak aortic jet velocity, $\mathrm{m} / \mathrm{s}$ & $3.7 \pm 0.6$ & $3.4 \pm 0.5$ & $4.4 \pm 0.5$ & $<0.001$ \\
\hline Mean aortic gradient, mm Hg & $34 \pm 13$ & $28 \pm 8$ & $47 \pm 12$ & $<0.001$ \\
\hline Effective orifice area, $\mathrm{cm}^{2}$ & $0.94 \pm 0.22$ & $1.04 \pm 0.20$ & $0.74 \pm 0.14$ & $<0.001$ \\
\hline Doppler stroke volume index, $\mathrm{mL} / \mathrm{m}^{2}$ & $43 \pm 13$ & $44 \pm 15$ & $41 \pm 10$ & 0.206 \\
\hline $\mathrm{PP} / \mathrm{SVi}, \mathrm{mm} \mathrm{Hg} / \mathrm{mL} / \mathrm{m}^{2}$ & $1.46 \pm 0.57$ & $1.44 \pm 0.56$ & $1.50 \pm 0.60$ & 0.512 \\
\hline $\mathrm{Z}_{\mathrm{va}}, \mathrm{mm} \mathrm{Hg} / \mathrm{mL} / \mathrm{m}^{2}$ & $4.37 \pm 1.25$ & $4.08 \pm 1.20$ & $4.85 \pm 1.19$ & $<0.001$ \\
\hline LV stroke work, g-m/bpm & $159.9 \pm 52.7$ & $161.3 \pm 56.7$ & $157.9 \pm 44.7$ & 0.606 \\
\hline
\end{tabular}

ARB, angiotensin II receptor blocker; AS, aortic stenosis; BP, blood pressure; LV, left ventricular; PP/SVi, pulse pressure/stroke volume index; $Z_{\mathrm{va}}$, valvuloarterial impedance; bpm, beats per minute.

\section{Predictors of early RR-HR during ETT}

Univariate predictors of RR-HR are presented in table 4. In a multivariate logistic regression analysis, older age, female sex, obesity and lower LV ejection fraction remained significant predictors of RR-HR (table 4). In the subset of patients without revealed symptoms, RR-HR was associated with female gender, coronary artery disease and lower LV ejection fraction (table 4).

\section{The association of early RR-HR during ETT with outcomes}

During a mean follow-up period of $34.9 \pm 34.6$ months, $254(84 \%)$ patients experienced an event, 226 AVR and
28 all-cause death. AVR occurred in $164(72 \%)$ of 229 with a normal HR response and in $62(81 \%$; $\mathrm{p}=0.151)$ of 77 with RR-HR. Death occurred in $20(8.7 \%)$ with a normal HR response and in eight $(10.4 \%$; $\mathrm{p}=0.679)$ with RR-HR. On univariate Cox regression analyses in the entire study population, RR-HR was associated with AVR (HR 1.75, 95\% CI 1.30 to 2.34; $\mathrm{p}<0.001$ ), but not with all-cause mortality (HR 1.97, 95\% CI 0.87 to 4.48 ; $\mathrm{p}=0.106)$. In the total population, after adjustment for age, sex, hypertension, coronary artery disease, abnormal BP response, Doppler stroke volume and 


\begin{tabular}{|c|c|c|c|c|}
\hline & Total $(n=306)$ & Moderate AS $(n=204)$ & Severe AS $(n=102)$ & $P$ value \\
\hline Pre-ETT heart rate, bpm & $77 \pm 15$ & $76 \pm 15$ & $78 \pm 16$ & 0.471 \\
\hline Pre-ETT systolic BP, mm Hg & $141 \pm 19$ & $141 \pm 19$ & $143 \pm 19$ & 0.395 \\
\hline Pre-ETT diastolic BP, mm Hg & $85 \pm 11$ & $84 \pm 11$ & $86 \pm 11$ & 0.098 \\
\hline Peak heart rate, bpm & $134 \pm 25$ & $134 \pm 26$ & $134 \pm 23$ & 0.802 \\
\hline Peak systolic BP, mm Hg & $166 \pm 26$ & $167 \pm 26$ & $165 \pm 25$ & 0.401 \\
\hline Peak diastolic BP, mm Hg & $90 \pm 16$ & $90 \pm 16$ & $91 \pm 16$ & 0.441 \\
\hline Abnormal BP response & $113(37 \%)$ & $72(36 \%)$ & $42(41 \%)$ & 0.388 \\
\hline Target heart rate achieved, \% & $86 \pm 15$ & $85 \pm 15$ & $89 \pm 14$ & 0.080 \\
\hline Rapid early rise in heart rate & $77(25 \%)$ & $49(24 \%)$ & $28(28 \%)$ & 0.452 \\
\hline Exercise duration, min & $9.7 \pm 4.4$ & $9.8 \pm 4.7$ & $9.6 \pm 3.6$ & 0.648 \\
\hline METs & $8.5 \pm 4.5$ & $9.0 \pm 4.8$ & $8.0 \pm 3.9$ & 0.063 \\
\hline Revealed symptoms & $87(28.4 \%)$ & $50(24.5 \%)$ & $37(36.3 \%)$ & 0.032 \\
\hline Double product, $\mathrm{mm} \mathrm{Hg} \cdot \mathrm{bpm}$ & $1.90 \pm 0.46$ & $1.91 \pm 0.48$ & $1.90 \pm 0.43$ & 0.874 \\
\hline
\end{tabular}

AS, aortic stenosis; BP, blood pressure; ETT, exercise treadmill test; METs, metabolic equivalents; bpm, beats per minute.

mean pressure gradient, RR-HR remained an independent predictor of AVR (HR 2.15, 95\% CI 1.44 to 3.22, $\mathrm{p}<0.001)($ table 5 ).

The symptom-free survival in patients with RR-HR was significantly lower at 1 and 2 years compared with those with normal HR response (figure 2A).

To determine whether RR-HR had prognostic use independent of revealed symptoms, we examined the subset of patients who were asymptomatic on the baseline ETT. RR-HR was a significant predictor of revealed symptoms developing spontaneously or on subsequent follow-up ETTs both in univariate (HR 1.82, 95\% CI 1.09 to 3.05 , $\mathrm{p}=0.022$ ) and multivariate Cox regression models (HR $2.14,95 \%$ CI 1.07 to $4.27, p=0.030$ ) (table 5). Symptom-free survival at 1 and 2 years in this subgroup was also significantly lower compared with patients with a normal HR response (figure 2B).

We further analysed patients with moderate and severe AS separately using univariate Cox regression models. In patients with moderate AS, RR-HR was associated with all-cause mortality (HR 2.67, 95\% CI 1.09 to 6.56, $\mathrm{p}=0.032$ ) and significantly lower 1 and 2 years freedom from all-cause mortality in Kaplan-Meier survival plots (figure 2C), but not with AVR (HR 1.35, 95\% CI 0.92 to $1.98, \mathrm{p}=0.127)$. By contrast, in patients with severe AS, RR-HR was associated with AVR (HR 3.32, 95\% CI 2.03 to $5.45, \mathrm{p}<0.001$ ) (figure 2D), but not with all-cause mortality (HR $0.04,95 \%$ CI 0.13 to $9.21, \mathrm{p}=0.798$ ). Similarly, in multivariate Cox regression analyses, the association between RR-HR and all-cause mortality in patients with moderate AS and between RR-HR and AVR in severe AS remained significant after adjustment for age, sex, hypertension, coronary artery disease, abnormal BP response, Doppler stroke volume and mean pressure gradient (table 6).

\section{DISCUSSION}

Exercise testing is recommended in asymptomatic severe AS to reveal symptoms or detect a BP drop which are class I and class IIa indications for AVR. ${ }^{1}$ We now describe a new exercise measurement with additional important prognostic implications, an early rapid rise in heart rate (RR-HR). This was associated with revealed symptoms later in the same test and predicted AVR in patients with severe AS and all-cause death in patients with moderate AS.

A RR-HR was associated with the development of symptoms later in the test. There is remaining uncertainty over the possible subjectivity of revealed symptoms as an indication for surgery. However, an associated haemodynamic change helps to corroborate its validity. We previously showed that the stroke volume falls at the start of exercise and before symptoms develop in patients with severe $\mathrm{AS}^{5}{ }^{5}$ Others have shown a failure of LV ejection fraction to rise as an adverse prognostic sign. ${ }^{19}$ We suggest that RR-HR is a compensatory mechanism to maintain cardiac output. Although the PPV for revealed symptoms was only $64 \%$, the NPV was $84 \%$ suggesting that in the presence of equivocal symptoms a normal HR response might provide reassurance. Conversely, if the result of ETT based on symptoms is inconclusive, a RR-HR may strengthen the clinical significance of symptoms and indicate a true positive ETT.

Clearly, patients with revealed symptoms have an indication for AVR. However, in patients who remained asymptomatic on baseline ETT, RR-HR predicted the development of revealed symptoms on serial testing suggesting that it has additional prognostic potential and might be used to identify a group for more frequent follow-up.

It was in patients with moderate AS that RR-HR might be most useful. This group is seen as having a benign 
Table 3 Baseline clinical, echocardiographic and ETT test data of the study population according to rate of heart rate rise during ETT

\begin{tabular}{|c|c|c|c|c|}
\hline & Total $(n=306)$ & $\begin{array}{l}\text { Normal HR response } \\
(n=229)\end{array}$ & $\begin{array}{l}\text { Rapid early rise in HR } \\
(\mathrm{n}=77)\end{array}$ & $P$ value \\
\hline \multicolumn{5}{|l|}{ Demographic and clinical data } \\
\hline Age, years & $65 \pm 12$ & $64 \pm 12$ & $70 \pm 10$ & $<0.001$ \\
\hline Male, Female \% & 67,33 & 70,30 & 56,44 & 0.024 \\
\hline Body mass index, $\mathrm{kg} / \mathrm{m}^{2}$ & $28 \pm 10$ & $27 \pm 4$ & $31 \pm 17$ & 0.060 \\
\hline Obesity & $80(26 \%)$ & $41(18 \%)$ & $35(46 \%)$ & $<0.001$ \\
\hline Coronary artery disease & $152(50 \%)$ & $106(46 \%)$ & $46(60 \%)$ & 0.062 \\
\hline Diabetes mellitus & $43(14 \%)$ & $28(12 \%)$ & $15(20 \%)$ & 0.093 \\
\hline Hypercholesterolaemia & $202(66 \%)$ & $148(65 \%)$ & $54(71 \%)$ & 0.326 \\
\hline Clinic systolic BP, mm Hg & $142 \pm 19$ & $141 \pm 19$ & $144 \pm 20$ & 0.225 \\
\hline Clinic diastolic BP, mm Hg & $82 \pm 13$ & $82 \pm 12$ & $82 \pm 15$ & 0.844 \\
\hline Hypertension & $223(73 \%)$ & $160(70 \%)$ & $63(82 \%)$ & 0.027 \\
\hline Beta blockers treatment & $101(33 \%)$ & $80(35 \%)$ & $21(27 \%)$ & 0.296 \\
\hline \multicolumn{5}{|l|}{ Echocardiographic data } \\
\hline Aortic root diameter, $\mathrm{cm}$ & $3.3 \pm 0.5$ & $3.4 \pm 0.5$ & $3.2 \pm 0.4$ & 0.028 \\
\hline Left atrium diameter, $\mathrm{cm}$ & $3.8 \pm 0.7$ & $3.7 \pm 0.7$ & $4.0 \pm 0.7$ & 0.006 \\
\hline LV end-diastolic diameter, $\mathrm{cm}$ & $4.6 \pm 0.7$ & $4.6 \pm 0.6$ & $4.5 \pm 0.7$ & 0.234 \\
\hline LV mass index, $\mathrm{g} / \mathrm{m}^{2.7}$ & $52 \pm 17$ & $52 \pm 16$ & $51 \pm 20$ & 0.320 \\
\hline LV ejection fraction, \% & $60 \pm 7$ & $61 \pm 7$ & $58 \pm 7$ & 0.030 \\
\hline Mean aortic gradient, $\mathrm{mm} \mathrm{Hg}$ & $34 \pm 13$ & $34 \pm 12$ & $36 \pm 17$ & 0.293 \\
\hline Effective orifice area, $\mathrm{cm}^{2}$ & $0.94 \pm 0.22$ & $0.95 \pm 0.22$ & $0.91 \pm 0.22$ & 0.213 \\
\hline Doppler stroke volume index, $\mathrm{mL} / \mathrm{m}^{2}$ & $43 \pm 13$ & $43 \pm 12$ & $41 \pm 15$ & 0.293 \\
\hline $\mathrm{Z}_{\mathrm{va}}, \mathrm{mm} \mathrm{Hg} / \mathrm{mL} / \mathrm{m}^{2}$ & $4.37 \pm 1.25$ & $4.25 \pm 1.17$ & $4.70 \pm 1.43$ & 0.034 \\
\hline \multicolumn{5}{|l|}{ ETT data } \\
\hline Pre-ETT heart rate, bpm & $77 \pm 15$ & $76 \pm 14$ & $79 \pm 16$ & 0.218 \\
\hline Pre-ETT systolic BP, mm Hg & $141 \pm 19$ & $141 \pm 19$ & $143 \pm 18$ & 0.290 \\
\hline Pre-ETT diastolic BP, mm Hg & $85 \pm 11$ & $85 \pm 11$ & $85 \pm 12$ & 0.860 \\
\hline Peak heart rate, bpm & $134 \pm 25$ & $134 \pm 27$ & $131 \pm 19$ & 0.257 \\
\hline Peak systolic BP, mm Hg & $166 \pm 26$ & $166 \pm 26$ & $167 \pm 26$ & 0.838 \\
\hline Peak diastolic BP, mm Hg & $90 \pm 16$ & $90 \pm 16$ & $90 \pm 18$ & 0.924 \\
\hline Target heart rate achieved, \% & $86 \pm 15$ & $86 \pm 16$ & $87 \pm 12$ & 0.377 \\
\hline Abnormal BP response & $113(37 \%)$ & $83(36)$ & $30(39)$ & 0.763 \\
\hline Exercise duration, min & $9.7 \pm 4.4$ & $11.2 \pm 3.9$ & $5.3 \pm 2.3$ & $<0.001$ \\
\hline METs & $8.5 \pm 4.5$ & $9.9 \pm 4.4$ & $5.0 \pm 2.5$ & $<0.001$ \\
\hline Revealed symptoms & $87(28.4 \%)$ & $38(16.6 \%)$ & $49(63.6 \%)$ & $<0.001$ \\
\hline
\end{tabular}

BP, blood pressure; ETT, exercise treadmill test; LV, left ventricular; METs, metabolic equivalents; $Z_{v a}$, valvuloarterial impedance; bpm, beats per minute.

prognosis but we showed that RR-HR predicted death even when corrected for age, gender, hypertension, coronary artery disease, abnormal BP response, Doppler stroke volume and mean pressure gradient. We and others have previously shown that $20 \%$ of patients with moderate AS develop revealed symptoms compared with $40 \%$ with severe AS. ${ }^{31}$ Patients with moderate AS have a significantly increased risk of myocardial infarction at the time of non-cardiac surgery, as demonstrated by Agrawal et al, 2.5\% compared with 3.5\% for severe AS and $1.0 \%$ for controls. ${ }^{7}$ This may partly be because of underestimation of the grade of AS or because of low aortic valve compliance or high combined $\mathrm{LV}$ outflow impedance. However, the presence of associated coronary artery disease is likely the most important factor. Patients with apparently moderate AS who are not exercised to reveal symptoms would not be considered for AVR leaving them at risk of dying from more severe AS 


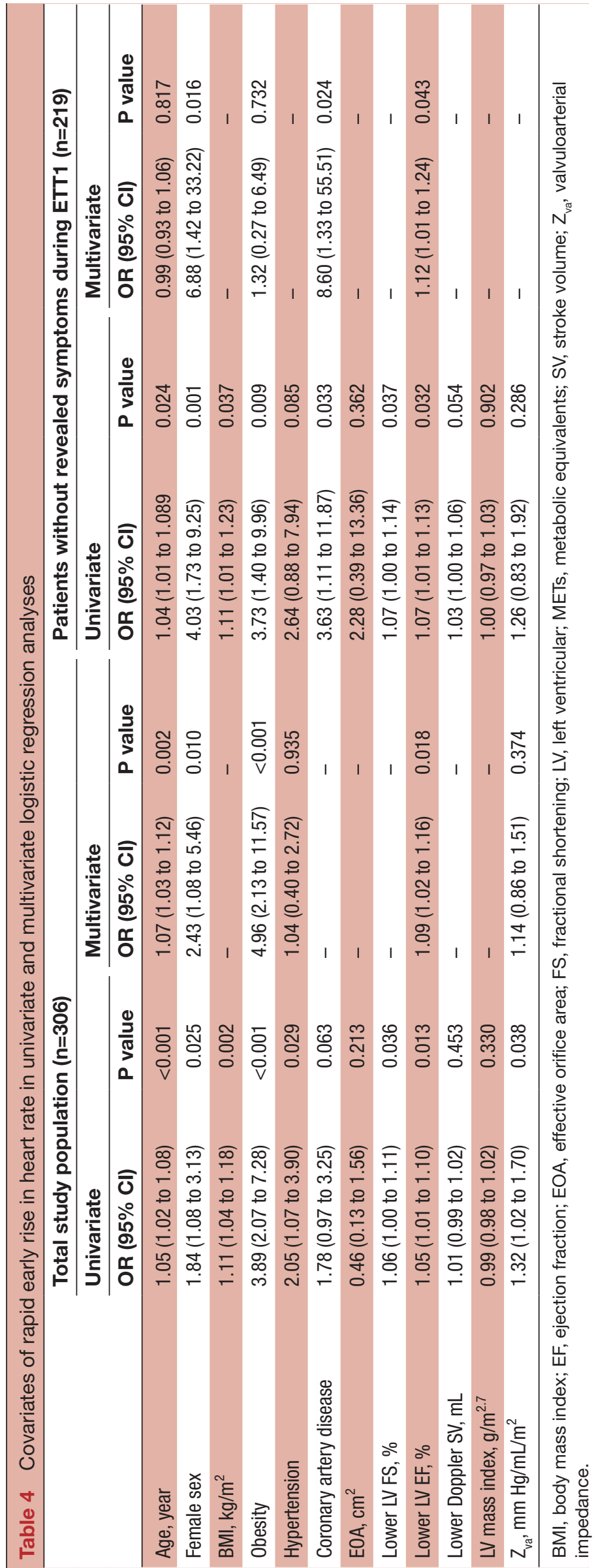


Table 5 Multivariate Cox regression analyses for AVR in the total population and for the development of spontaneous or revealed symptoms on serial testing in patients who were asymptomatic on the baseline study

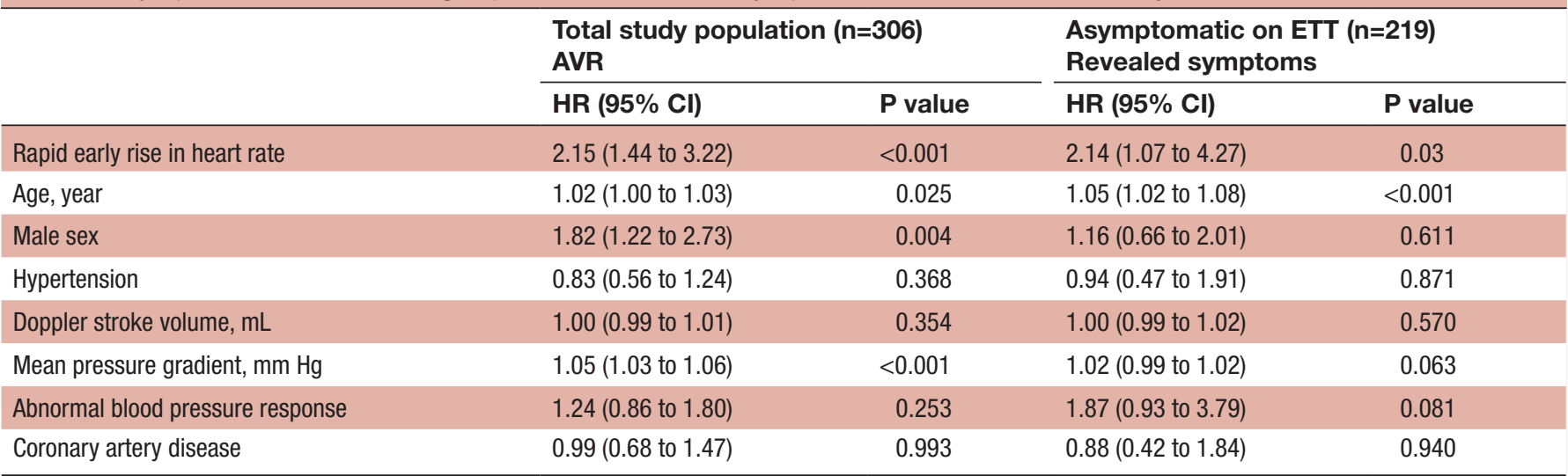

AVR, aortic valve replacement; ETT, excercise treadmill test.

than realised or associated coronary artery disease or both. Death might occur spontaneously or at the time of non-cardiac surgery or a major trauma or illness for

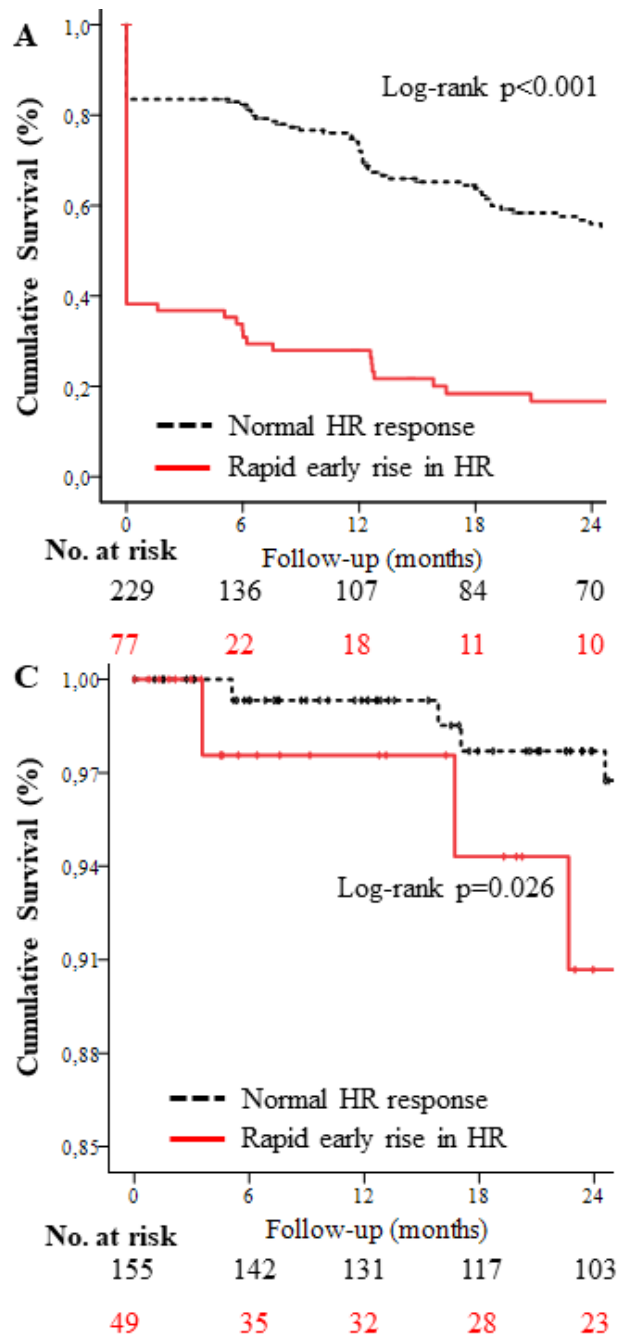

which the AS reduces cardiac reserve. ${ }^{22}$ Our patients with moderate AS had a higher prevalence of hypercholesterolaemia and coronary artery disease and a comparable

Figure 2 Kaplan-Meier curves showing the probability of symptom-free survival according to the rate of heart rate rise during exercise testing in (A) for the whole study population, and in (B) for the subset of patients who did not develop revealed symptoms on the baseline exercise test and $(C)$ shows event-free survival from all-cause mortality in patients with moderate aortic stenosis and (D) shows event-free survival from aortic valve replacement in patients with severe aortic stenosis. 
Table 6 Multivariate Cox regression analyses for all-cause mortality in patients with moderate AS or AVR in patients with severe AS

\begin{tabular}{|c|c|c|c|c|}
\hline & \multicolumn{2}{|l|}{ Moderate AS $(n=204)$} & \multicolumn{2}{|c|}{ Severe AS $(n=102)$} \\
\hline & \multicolumn{2}{|l|}{ All-cause mortality } & \multicolumn{2}{|l|}{ AVR } \\
\hline & HR (95\% Cl) & P value & HR (95\% Cl) & $P$ value \\
\hline Rapid early rise in heart rate & 16.02 (1.83 to 140.02$)$ & 0.012 & 3.21 (1.70 to 6.08$)$ & $<0.001$ \\
\hline Age, year & 1.13 (1.01 to 1.23$)$ & 0.044 & $1.00(0.97$ to 1.03 & 0.897 \\
\hline Male sex & 8.37 (0.43 to 165.06$)$ & 0.162 & 2.16 (1.08 to 4.29$)$ & 0.029 \\
\hline Hypertension & $0.11(0.01$ to 2.11$)$ & 0.143 & 0.90 (0.44 to 1.87$)$ & 0.781 \\
\hline Doppler stroke volume, mL & 1.00 (0.95 to 1.05$)$ & 0.990 & 0.99 (0.98 to 1.01$)$ & 0.733 \\
\hline Mean pressure gradient, mm Hg & 1.17 (1.00 to 1.36$)$ & 0.045 & 1.03 (1.00 to 1.05$)$ & 0.043 \\
\hline Abnormal blood pressure response & 0.19 (0.02 to 2.24$)$ & 0.185 & 1.86 (1.00 to 3.44 & 0.049 \\
\hline Coronary artery disease & $14.63(0.42$ to 514.15$)$ & 0.140 & 1.35 (0.74 to 2.47$)$ & 0.333 \\
\hline
\end{tabular}

AS, aortic stenosis; AVR, aortic valve replacement.

prevalence of hypertension-mediated organ damage compared with those with severe AS. These factors are also associated with a higher rate of progression of AS. ${ }^{23}$ A RR-HR might therefore be an indication for further evaluation of patients with apparently moderate AS, for example, with stress echocardiography looking for wall motion abnormalities.

There is little previously published work for comparison. In patients with coronary artery disease, a RR-HR in the first 1 min of individualised bicycle exercise defined as $\geq 12 \mathrm{bpm}$ above the median increase predicted a higher risk of death and non-fatal myocardial infarction than in those with a normal rise in $\mathrm{HR} .{ }^{24}$ An excessive HR increase in response to mental stress before exercise in the general population is also associated with a relatively high risk of sudden death and non-cardiac deaths. ${ }^{25}$ By contrast, a study using standardised treadmill exercise similar to our methodology showed that HR-RR was associated with a relatively low risk of cardiac events in patients referred for clinical exercise testing including some with coronary artery disease. ${ }^{26}$ There is little comparable literature in patients with AS as studies have mainly focused on symptoms and BP response. ${ }^{142127-29}$ We showed several other risk factors including higher age, male gender and mean pressure gradient were associated with all-cause mortality or risk of AVR as already shown. ${ }^{30}$

\section{Limitations}

This was a retrospective analysis of prospectively collected clinical information but the information on hospital databases was close to complete. We did not perform routine stress echocardiography to look for changes in transaortic gradient and the development of wall motion abnormalities or pulmonary hypertension. The definition of RR-HR was arbitrary but based on clinical judgement, and it is possible that better thresholds could be determined using a larger database.

\section{CONCLUSIONS}

An early RR-HR during ETT was associated with the development of revealed symptoms later in the same ETT. In patients who remained asymptomatic on exercise, it predicted revealed symptoms on serial ETT and predicted AVR in severe AS and all-cause mortality in moderate AS. We believe this new measure should be included with symptom onset and BP response in research studies and it may in the future help decide on the need for surgery or further investigation.

Acknowledgements The authors thank the participants of the EXTAS study for their important contributions.

Funding The authors have not declared a specific grant for this research from any funding agency in the public, commercial or not-for-profit sectors.

Competing interests None declared.

Patient consent for publication Not required.

Ethics approval The study was approved by the local institutional review board (Study Protocol n. 7461/2017).

Provenance and peer review Not commissioned; externally peer reviewed.

Data sharing statement No additional data are available.

Open access This is an open access article distributed in accordance with the Creative Commons Attribution Non Commercial (CC BY-NC 4.0) license, which permits others to distribute, remix, adapt, build upon this work non-commercially, and license their derivative works on different terms, provided the original work is properly cited, appropriate credit is given, any changes made indicated, and the use is non-commercial. See: http://creativecommons.org/licenses/by-nc/4.0/.

\section{REFERENCES}

1. Baumgartner H, Falk V, Bax JJ, De Bonis M, et al. 2017 ESC/EACTS Guidelines for the management of valvular heart disease. Eur Heart $J$ 2017;38:2739-91.

2. lung $B$, Baron $G$, Butchart EG, et al. A prospective survey of patients with valvular heart disease in Europe: the euro heart survey on valvular heart disease. Eur Heart J 2003;24:1231-43.

3. Saeed S, Rajani R, Seifert R, et al. Exercise testing in patients with asymptomatic moderate or severe aortic stenosis. Heart 2018;104:1836-42.

4. Singh A, Greenwood JP, Berry C, et al. Comparison of exercise testing and CMR measured myocardial perfusion reserve for predicting outcome in asymptomatic aortic stenosis: the PRognostic Importance of Mlcrovascular Dysfunction in Aortic Stenosis (PRIMID AS) Study. Eur Heart J 2017;38:1222-9. 
5. Rajani R, Rimington $\mathrm{H}$, Chambers JB. Treadmill exercise in apparently asymptomatic patients with moderate or severe aortic stenosis: relationship between cardiac index and revealed symptoms. Heart 2010;96:689-95.

6. Rosenhek R, Klaar U, Schemper M, et al. Mild and moderate aortic stenosis. Natural history and risk stratification by echocardiography. Eur Heart J 2004;25:199-205.

7. Agarwal S, Rajamanickam A, Bajaj NS, et al. Impact of aortic stenosis on postoperative outcomes after noncardiac surgeries. Circ Cardiovasc Qual Outcomes 2013;6:193-200.

8. Otto CM. Aortic stenosis: even mild disease is significant. Eur Heart J 2004:25:185-7.

9. Nishimura RA, Otto CM, Bonow RO, et al. 2017 AHA/ACC focused update of the 2014 AHA/ACC guideline for the management of patients with valvular heart disease: a report of the American college of cardiology/american heart association task force on clinical practice guidelines. Circulation 2017;135:e1159-95.

10. Joint Task Force on the Management of Valvular Heart Disease of the European Society of Cardiology (ESC), European Association for Cardio-Thoracic Surgery (EACTS), Vahanian A, et al. Guidelines on the management of valvular heart disease (version 2012). Eur Heart $J$ 2012;33:2451-96.

11. Schutte S, Thijs L, Asayama K. International database on ambulatory blood pressure in relation to cardiovascular outcomes (IDACO) Investigators. Double product reflects the predictive power of systolic pressure in the general population: evidence from 9,937 participants. Am J Hypertens 2013;26:665-72.

12. Gibbons RJ, Balady GJ, Bricker JT, et al. ACC/AHA 2002 guideline update for exercise testing: summary article: a report of the American college of Cardiology/American heart association task force on practice guidelines (Committee to Update the 1997 Exercise Testing Guidelines). Circulation 2002;106:1883-92.

13. Bruce RA. Exercise testing methods and interpretation. Adv Cardiol 1978;24:6-15.

14. Magne J, Lancellotti P, Piérard LA. Exercise testing in asymptomatic severe aortic stenosis. JACC Cardiovasc Imaging 2014;7:188-99.

15. Jetté M, Sidney K, Blümchen G. Metabolic equivalents (METS) in exercise testing, exercise prescription, and evaluation of functional capacity. Clinical Cardiology 1990;13:555-65.

16. Astrand I. Aerobic work capacity in men and women with special reference to age. Acta Physiol Scand Suppl 1960;49:1-92.

17. Gerdts E, Rossebø AB, Pedersen TR, et al. Relation of left ventricula mass to prognosis in initially asymptomatic mild to moderate aortic valve stenosis. Circ Cardiovasc Imaging 2015;8:e003644.
18. de Simone G, Roman MJ, Koren MJ, et al. Stroke volume/pulse pressure ratio and cardiovascular risk in arterial hypertension. Hypertension 1999;33:800-5.

19. Maréchaux S, Ennezat P-V, LeJemtel TH, et al. Left ventricular response to exercise in aortic stenosis: an exercise echocardiographic study. Echocardiography 2007;24:955-9.

20. Hachicha Z, Dumesnil JG, Bogaty P, et al. Paradoxical low-flow, lowgradient severe aortic stenosis despite preserved ejection fraction is associated with higher afterload and reduced survival. Circulation 2007;115:2856-64.

21. Lancellotti P, Lebois F, Simon M, et al. Prognostic importance of quantitative exercise doppler echocardiography in asymptomatic valvular aortic stenosis. Circulation 2005;112(9 Suppl):I377-82.

22. Berry C, Lloyd SM, Wang Y, et al. The changing course of aortic valve disease in Scotland: temporal trends in hospitalizations and mortality and prognostic importance of aortic stenosis. Eur Heart $J$ 2013;34:1538-47.

23. Kamath $A R, P a i$ RG. Risk factors for progression of calcific aortic stenosis and potential therapeutic targets. Int $J$ Angiol 2008;17:63-70.

24. Falcone C, Buzzi MP, Klersy C, et al. Rapid heart rate increase at onset of exercise predicts adverse cardiac events in patients with coronary artery disease. Circulation 2005;112:1959-64.

25. Jouven X, Schwartz PJ, Escolano S, et al. Excessive heart rate increase during mild mental stress in preparation for exercise predicts sudden death in the general population. Eur Heart $J$ 2009;30:1703-10.

26. Leeper NJ, Dewey FE, Ashley EA, et al. Prognostic value of heart rate increase at onset of exercise testing. Circulation 2007;115:468-74.

27. Rafique AM, Biner S, Ray I, et al. Meta-analysis of prognostic value of stress testing in patients with asymptomatic severe aortic stenosis. Am J Cardiol 2009;104:972-7.

28. Amato MC, Moffa PJ, Werner KE, et al. Treatment decision in asymptomatic aortic valve stenosis: role of exercise testing. Heart 2001;86:381-6.

29. Alborino D, Hoffmann JL, Fournet PC, et al. Value of exercise testing to evaluate the indication for surgery in asymptomatic patients with valvular aortic stenosis. J Heart Valve Dis 2002;11:204-9.

30. Maréchaux S, Hachicha Z, Bellouin A, et al. Usefulness of exercise-stress echocardiography for risk stratification of true asymptomatic patients with aortic valve stenosis. Eur Heart $J$ 2010;31:1390-7. 